\title{
EDUCAÇÃO DO CAMPO: EMBATE ENTRE MOVIMENTO CAMPONÊS E ESTADO
}

Marlene Ribeiro*

RESUMO: O artigo trata do embate entre os diferentes movimentos sociais populares do campo, identificados na unidade provisória Movimento Camponês, que demandam a educação do campo voltada aos seus modos de vida e de trabalho, e o Estado brasileiro, no que concerne aos programas governamentais oferecidos em resposta a essa deman$\mathrm{da}^{1}$. Visa a apontar potencialidades da educação do campo, enquanto conquista do Movimento Camponês, e os limites que esta enfrenta, no Brasil, em que o capital agrário e financeiro, relacionado ao agronegócio, disputa a propriedade da terra e exerce pressão sobre o Estado. A importância deste trabalho está em promover uma reflexão sobre os desafios colocados ao Movimento Camponês, enquanto este orienta suas ações por um projeto societário em visível confronto com o modelo neoliberal de sociedade no qual se sustentam as ações do Estado brasileiro.

Palavras-chave: Educação do Campo. Movimentos Sociais. Políticas Públicas.

\section{RURAL EDUCATION:}

\section{CONFLICTS BETWEEN THE PEASANT MOVEMENT AND THE STATE}

ABSTRACT: The article discusses the conflicts between the Brazilian state and the different popular social movements of the countryside, especially the ones identified in the Peasant Movement's provisional unit, which call for education to support a return to a rural way of life and work, looking for government policies that respond to this demand. It also aims to point out the potential, (as a Peasant Movement of conquest), that the rural education movement has, and the limits it faces, in Brazil, where it comes head to head with (in direct conflict with) agrarian and financial capital (or funding, e.g. of the state), associated with agro-business. At the same time, agri-business's protagonists dispute the (peasant) movement's ownership of, or right to, land and put pressure on the State to back their agenda. The importance of this paper is in providing a reflection on the challenges facing the Peasant Movement as it directs its actions in accordance with a socially-geared project, clearly in opposition to the neoliberal model of society while this model continues to exercise its influence on the Brazilian state.

Keywords: Rural Education. Social Movements. Public or State Policies.

\footnotetext{
* Doutora em Educação pela Universidade Federal do Rio Grande do Sul (UFRGS); Professora do Programa de Pós-Graduação em Educação da Universidade Federal do Rio Grande do Sul (UFRGS) e coordenadora do Grupo de Pesquisa Trabalho, Movimentos Sociais e Educação (TRAMSE). E-mail: maribe@adufrgs.ufrgss.br
} 


\section{Introdução}

O artigo trata do embate entre o Movimento Camponês - o que ele demanda como educação do campo, e o Estado brasileiro - e o que o Estado oferece como política educacional para populações que vivem e trabalham na zona rural. O Movimento Camponês é uma unidade em processo de construção, por isso caracterizado como um sujeito políticocoletivo; é constituído por uma diversidade de formas assumidas pelos movimentos sociais populares, que se organizam para enfrentar os desafios próprios das relações sociais peculiares ao trabalho no e do campo, no Brasil. À educação rural - como negação histórica dos agricultores enquanto sujeitos da produção de alimentos, culturas e saberes - movimentos sociais populares contrapõem a educação do campo, um projeto coletivo incorporado no processo de luta pela terra de trabalho.

Por sua vez, o Estado, sob forte influência do movimento liberal reacionário dos anos de 1990, adota políticas educacionais definidas pelos organismos multilaterais, entre estes o Banco Mundial, como condição para a efetivação de empréstimos solicitados pelo Brasil. Nesse contexto, o Ministério da Educação - MEC retoma a concepção liberal de "escola nova", de Dewey, revestindo-a de uma nova versão, por meio do Programa Escola Ativa aplicado à gestão e à formação de professores das classes multisseriadas de $1^{\mathrm{a}}$ a $4^{\mathrm{a}}$ série do ensino fundamental, existentes nas áreas rurais. Com isso, efetua-se a reedição, em novo contexto e como resposta a questões distanciadas das que lhes deram origem, de concepções disseminadas no Brasil, durante a primeira metade do século XX, no processo de desenvolvimento industrial capitalista, considerando o avanço do Movimento Operário, em vários países (HEIJMANS, 2006; RIBEIRO, 2009). O objetivo deste trabalho é, portanto, apontar as contradições que atravessam as relações, caracterizadas como de embate, entre o Movimento Camponês e o Estado, em se tratando da educação rural/do campo e tendo como pano de fundo a disputa pela terra entre os agricultores familiares e o capital agrário e financeiro, relacionado ao agronegócio'.

O novo trazido pela educação do campo, proposta pelo Movimento Camponês, consiste na articulação entre o trabalho na agricultura, na pecuária e na pesca, no chamado Tempo-Comunidade, com os estudos teórico-práticos efetuados no chamado Tempo-Escola. Nesse segundo período, ou seja, na escola, realizam-se estudos visando a encon- 
trar respostas aos problemas evidenciados no Tempo-Comunidade, uma vez que a formação proposta pelo Movimento Camponês está articulada, de modo indissociável, ao trabalho no e do campo. Este método, em que se combinam trabalho e educação, é adotado em muitos países, incluindo o Brasil, como pedagogia da alternância ${ }^{2}$, embora, na Via CampesinaBrasil $^{3}$, assuma contornos diferenciados. Todavia, não se pretende fazer a análise dessas experiências, em suas semelhanças e diferenças, o que foi feito por Ribeiro (2010), na obra em que analisa os princípios/ fins da formação humana que vem sendo efetuada pelo Movimento Camponês, quando relaciona trabalho e educação.

O foco do artigo está direcionado para o embate que se trava entre o Movimento Camponês e o Estado, tendo por objeto de disputa a educação do campo. Nesse sentido, as contradições podem ser evidenciadas nas concepções/práticas de educação do campo, e na busca de recursos públicos para efetivá-las, por parte do Movimento Camponês, de um lado, e do que vem sendo aplicado como política educacional pelo Ministério da Educação - MEC, de outro. No primeiro caso, selecionamos a Escola Itinerante dos acampamentos do Movimento dos Trabalhadores Sem Terra (MST) e o Programa Nacional de Educação da Reforma Agrária (PRONERA), vinculado ao Instituto Nacional de Colonização e Reforma Agrária (INCRA), órgão do Ministério do Desenvolvimento Agrário (MDA). No segundo caso, com relação à política de Estado para a educação das populações rurais, selecionamos o Programa Escola Ativa, sob a responsabilidade do MEC.

Devido à multiplicidade e à riqueza de experiências de educação do campo, tais como: ciranda infantil para a pré-escola, ensino fundamental, médio e profissional, incluindo a educação de jovens e adultos - EJA, ensino superior de graduação, com bacharelado e licenciatura, e de pósgraduação, optou-se por abordar a Escola Itinerante, dos acampamentos, em que os conflitos podem ser mais claramente evidenciados. Do mesmo modo, incluímos o PRONERA, uma vez que a existência ou não dos recursos públicos é determinante na consecução das experiências que estão relacionadas, principalmente, às classes de ensino regular, da educação infantil à universidade. Isso quanto à demanda de educação do campo proveniente do sujeito político coletivo Movimento Camponês. Quanto às políticas públicas para a educação, destinadas às populações que vivem nas áreas rurais, destacamos o Programa Escola Ativa, administrado pelo 
Fundo de Fortalecimento da Escola - Fundescola, com financiamento do Banco Mundial, no período de 1997 a 2007, tendo continuidade, após esse período, como política de Estado, sob a responsabilidade do MEC.

As questões que orientam a abordagem feita neste artigo são: Por que a Escola Itinerante, que acompanha o deslocamento das famílias acampadas à espera da desapropriação de terras próprias para a reforma agrária, cuja proposta pedagógica foi aprovada no estado do Rio Grande do Sul, em 1996, estendendo-se a outros estados, foi proibida pelo Ministério Público/RS de funcionar no estado em que teve origem? Por que, conquistado em 1998, como resultado da I Conferência Por uma Educação Básica do Campo, o PRONERA fica impedido de ser executado pelo Acórdão 2.653/2008, do Tribunal de Contas da União - TCU e, mesmo tendo este suspendido os efeitos da decisão, os recursos não são repassados para o pagamento correspondente aos convênios com as entidades que efetuam a formação em educação do campo? E ainda: por que, se já existe uma reflexão e uma proposta concreta de formação humana que articula trabalho-escola, como educação do campo, demandada pelo Movimento Camponês e reconhecida pelo MEC, o Estado brasileiro, em cuja estrutura se integra este Ministério, reedita a concepção liberal de escola ativa sobrepondo-se à educação do campo?

Para responder às indagações e dentro dos limites de um artigo, a ideia é refazer o caminho da Escola Itinerante desde o estado/RS, onde começou, e, do mesmo modo, resgatar a conquista do PRONERA, trazendo alguns resultados de sua aplicação. Essas ações - Escola Itinerante e PRONERA - definem o seu propositor, o Movimento Camponês, como um sujeito político coletivo em busca de transformações de caráter social e educacional. De outro lado, o olhar estará direcionado ao Programa Escola Ativa, adotado nas regiões Norte, Nordeste e CentroOeste do Brasil, no período em que foi financiado pelo Banco Mundial, tendo chegado à região Sul a partir de 2008. A opção pelo Programa Escola Ativa, em contraposição à educação do campo, por parte do Estado, é entendida como uma atitude de reação, que fica mais clara com a proibição de funcionamento das escolas itinerantes e com a decisão do TCU quanto à utilização dos recursos do PRONERA.

Levanta-se a hipótese de que a educação rural, amplamente criticada como negação histórica dos sujeitos que vivem do trabalho com a terra - os agricultores familiares -, substituída pelo MEC por uma con- 
cepção liberal, a escola ativa, com características civilizatórias e urbanocêntricas de "preparação para o trabalho", é no sentido de subtrair a educação do campo conquistada pelo Movimento Camponês. No embate com esse Movimento, a resposta do Estado, ao optar pelo Programa Escola Ativa, parece, assim, identificar-se como uma reação.

Aprofundar-se-á a análise desse processo caracterizado pelo movimento de ação/reação enfocando, de um lado, a Escola Itinerante do MST, impedida de continuar funcionando nos acampamentos dos trabalhadores sem-terra, no estado/RS, ainda que anteriormente tenha sido aprovada pelo Conselho Estadual de Educação - CEED. E, de igual modo, a proibição de liberação dos recursos do PRONERA para a execução dos cursos oferecidos por universidades e institutos federais, mesmo tendo seus projetos já aprovados. De outro, a prática/concepção de escola nova que informa o Programa Escola Ativa, como política adotada pelo MEC para as escolas multisseriadas rurais de ensino fundamental, da $1^{\mathrm{a}}$ a $4^{a}$ série, sobrepondo-se ao acúmulo de experiências e conhecimentos em educação do campo, por parte de educadores, pesquisadores e instituições que têm participado da formação nessa área.

A importância de organizar e sistematizar elementos para comprovar essa hipótese está em promover uma reflexão sobre os desafios colocados à educação do campo, uma vez que o Movimento Camponês orienta suas ações por um projeto societário em visível confronto com o modelo de sociedade capitalista no qual se sustentam as ações do Estado brasileiro.

\section{Educação do campo conquistada na luta pela terra de trabalho}

Para compreender a educação do campo, dentro da qual se insere a proposta de Escola Itinerante, é necessário situá-la na trajetória de constituição do Movimento dos Trabalhadores Rurais Sem Terra - MST, que dá continuidade às lutas históricas do campesinato brasileiro. Embora a função social da terra já estivesse assegurada no Estatuto da Terra - Lei n. 4.504 de 30/11/1964, da ditadura militar (CONTAG, 1979), foi preciso que os milhares de trabalhadores sem-terra se organizassem na busca pela terra de trabalho, iniciada em 1979, ainda na vigência dessa ditadura. Nesse processo de enfrentamento com o Estado, para a ocupação de ter- 
ras improdutivas ou devolutas ou daquelas sobre as quais os latifundiários não pagam os devidos impostos, processo este do qual são vítimas fatais muitos trabalhadores, nasce o MST, oficialmente em 1985, durante o $1^{\circ}$ Congresso Nacional dos Trabalhadores Rurais (GOHN, 1995; MORISSAWA, 2001; BEZERRA NETO, 1999).

Mas, à medida que ocupam a terra com suas famílias, nos assentamentos designados pelo Estado, sob a orientação do INCRA, os agricultores começam a demandar uma escola para os filhos, porém diferente da escola rural que, historicamente, lhes tem sido oferecida (CALAZANS, 1993; GRITTI, 2003; DAMASCENO; BEZERRA, 2004). Educadores assentados, junto com agentes da Comissão Pastoral da Terra - CPT, que tem apoiado o Movimento Camponês, organizam-se para formular uma proposta pedagógica direcionada à formação humana, portanto, articulando trabalho-educação. Assim, com o apoio da Articulação Nacional por uma Educação do Campo, que reúne diferentes entidades de caráter social $^{4}$, além do MST, realiza-se a I Conferência: Por uma Educação Básica do Campo, em Luziânia, estado de Goiás, em 1998. Nessa Conferência, amplia-se a demanda pela educação do campo com a participação de todos os movimentos sociais populares do campo, organizados na Via Campesina ${ }^{5}$-Brasil, bem como os sindicatos de trabalhadores rurais, as federações e a Confederação Nacional dos Trabalhadores na Agricultura - CONTAG ${ }^{6}$.

No mesmo ano da I Conferência e como resultado desta é criado o Programa Nacional da Educação da Reforma Agrária - PRONERA, vinculado ao INCRA, pelo Ministério Extraordinário de Política Fundiária, no governo de Fernando Henrique Cardoso; no atual governo, trata-se do Ministério do Desenvolvimento Agrário - MDA. Aqui já se evidencia uma contradição no fato de o PRONERA, destinado a fomentar uma política educacional para as populações trabalhadoras rurais, estar vinculado ao INCRA/MDA e não ao MEC.

Antecede a I Conferência Por uma Educação Básica do Campo o I Encontro Nacional de Educadores e Educadoras da Reforma Agrária - ENERA, em julho de 1997, promovido pelo MST, com o apoio das mesmas entidades que subsidiaram aquela Conferência. Observe-se que, nesse mesmo ano, ou seja, em 1997, é criado o Fundo de Fortalecimento da Escola - Fundescola, através do qual foi implementado o Programa Escola Ativa, pelo MEC. Isso porque, conforme se pode observar na aná- 
lise que será feita adiante, contando com o financiamento do Banco Mundial, esse Programa se destinava a introduzir novas concepções/práticas de gestão das escolas multisseriadas rurais, através da formação de seus professores e do fornecimento de material didático adequado à sua proposta.

Levadas ao Conselho Nacional de Educação - CNE as preocupações dos educadores que participaram do I ENERA, este Conselho aprova a Resolução CNE/CEB 1, de 03/04/2002, que institui as Diretrizes Operacionais para a Educação Básica nas Escolas do Campo. O Parecer final confirma a necessidade da educação pública do campo em substituição à educação rural, que em nada se diferencia da educação urbana, a não ser na precariedade maior das condições de sua oferta às populações rurais. Maria do Socorro Silva, em obra organizada por educadoras ligadas ao Movimento Sindical de Trabalhadores e Trabalhadoras Rurais - MSTTR, que integram a Comissão de Educação da CONTAG, faz uma crítica à educação que tem sido oferecida às famílias de trabalhadores rurais. Diz no seu artigo (SILVA, 2009 , p. 35) ser a escola rural urbanocêntrica, pelos conteúdos voltados ao processo de urbanização e industrialização; sócio-cêntrica e comprometida com os interesses das elites sem considerar a diversidade de culturas existentes no campo; etnocêntrica, uma vez que privilegia os conhecimentos relacionados ao mundo ocidental, industrializado.

A educação do campo defendida pelo Movimento Camponês traz implícitos: a) o vínculo entre a educação e a garantia da terra de trabalho; b) a superação da escola rural portadora de currículo, conteúdo e metodologia voltados à valorização do trabalho e da cultura urbanos; c) a identificação com o campo enquanto espaço político de disputas históricas dos agricultores familiares pela conquista da e permanência na terra de trabalho; d) a relação entre o trabalho desenvolvido na agricultura, na pesca e na pecuária, associado ao currículo, ao conteúdo e ao método adotados pela escola do campo; e) o reconhecimento dos agricultores familiares como sujeitos de educação e produtores de alimentos, saberes, conhecimentos e culturas (RIBEIRO, 2010). Assim, diante da questão agrária, a educação enquanto formação humana "tem a função primeira de indagar dos sujeitos seu papel no campo a partir dos vínculos com a terra" (MOLINA, 2004, p. 75).

Destaca-se, antes ainda de entrar na abordagem da Escola Itinerante - isso será feito na sequência -, que, tanto as Diretrizes 
Operacionais (Resolução CNE/CEB n. 1 de 03/04/2002), quanto o PRONERA, não foram instituídos por iniciativa do Estado. Foram, sim, respostas dadas sob a pressão do Movimento Camponês. Outro destaque é que esse Movimento, constituído de uma diversidade de sujeitos trabalhadores, como já afirmado, organiza-se e ganha força em um contexto de ressurgimento dos movimentos sociais populares, nos anos de 1980. Organizações populares pressionam e conquistam, em 1985, a entrega do governo exercido pela ditadura militar para um governo civil, embora resultante de eleição indireta, e, em 1988, a nova Constituição da República Federativa do Brasil ${ }^{8}$. Registra-se, ainda, um último destaque como auxílio à confirmação da hipótese de trabalho. Trata-se da existência de estudos apontando que, apesar de terem ocorrido avanços, como a conquista de cursos em nível superior e de especialização, efetuados por universidades federais e estaduais, os projetos aprovados pelo INCRA/PRONERA enfrentam graves problemas para a liberação dos recursos já aprovados, no MDA, conforme veremos na abordagem após a Escola Itinerante.

\section{Itinerante:}

\section{uma escola que se faz ao caminhar}

Trazendo agora o debate para a Escola Itinerante, esta foi conquistada pelo MST, integrante da Via Campesina-Brasil, tendo sido inicialmente aprovada como proposta pedagógica, em 1996, no estado do Rio Grande do Sul, e ampliada para outros estados da federação brasileira. O nome que lhe foi dado - Itinerante - não é um termo novo. A história registra a adoção dessa modalidade de ensino, destinado às populações suburbanas ou moradoras de locais onde não funcionavam escolas, em 1890, no Brasil'. Já no Movimento Camponês, a preocupação dos pais com a educação dos filhos está presente desde o início da luta dos agricultores para a conquista da escola associada ao trabalho, pois a realidade acabava por confirmar a possibilidade de estender-se por mais de um ano o período durante o qual permaneceriam acampados. Porém, a construção de uma escola no acampamento poderia inviabilizar o deslocamento das famílias. O que fazer? Pensou-se, então, que uma "escola de caráter itinerante viria para mover-se à medida que os acampamentos teriam de se mobilizar" (CAMINI, 2009, p. 105). 
De início, não havia reflexões e estudos sobre uma escola "diferente", voltada ao trabalho e ao modo de vida dos agricultores. Com isso, o Setor de Educação do MST foi mobilizado e estimulado a criar, em 1990, cursos de magistério em nível médio, efetuando-se estes na Fundação de Desenvolvimento, Educação e Pesquisa da Região Celeiro FUNDEP, deslocando-se, mais tarde, para o Instituto Técnico de Capacitação e Pesquisa da Reforma Agrária - ITERRA, ambos no estado do Rio Grande do Sul. Contudo, até 1996, ainda não havia o reconhecimento oficial das escolas itinerantes que funcionavam nos acampamentos; as crianças que conseguiam frequentar escolas públicas situadas nas proximidades dos acampamentos eram desligadas quando eles mudavam de lugar.

Encontros estaduais de crianças sem-terra são realizados no Rio Grande do Sul, nos anos de 1994 e 1996, e em São Paulo, em 1997, estendendo-se para outros estados e passando a chamar-se, a partir de então, Encontros dos Sem Terrinha. Nesses encontros é debatida e construída uma proposta pedagógica para a Escola Itinerante dos agricultores acampados, oferecendo, principalmente, as quatro séries iniciais do ensino fundamental para crianças e a EJA aos analfabetos. Levada ao Conselho Estadual de Educação - CEED/RS, a proposta é aprovada, sob o Parecer n. 1313/96, com o nome de "Experiência pedagógica - Escola Itinerante, tendo como Escola-Base a Escola Estadual de $1^{\circ}$ Grau Nova Sociedade, do assentamento Itapuí, no município de Nova Santa Rita/RS, escola que responde por todo o processo organizativo e institucional da Escola Itinerante" (MST, 2003, p. 100, com grifos no original) ${ }^{10}$. Já em 2008, estavam organizadas escolas itinerantes em oito acampamentos, no estado/RS, com 40 educadores, a maioria com o curso de magistério, em nível médio, ou de Pedagogia da Terra, ou, ainda, de licenciatura em Educação do Campo.

Somente no ano de 2003, no entanto, a Escola Itinerante estende-se aos acampamentos dos sem-terra nos estados do Paraná, com onze escolas, em Santa Catarina, com doze escolas; nos dois estados a proposta pedagógica é aprovada no ano de 2004. No estado de Goiás, o processo organizativo dos acampamentos se inicia em 1999, porém a proposta só é aprovada em 2005, aberta a outros movimentos sociais populares. Nesse ano, a Escola Itinerante é aprovada também no estado de Alagoas e, do mesmo modo, estendida a outros movimentos sociais populares de 
luta pela terra, tendo já em funcionamento quatro escolas. No estado do Piauí funcionam quatro escolas itinerantes com a proposta aprovada em 2008. Com isso, temos a Escola Itinerante reconhecida em seis estados da federação brasileira, embora impedida de funcionar em um deles, o Rio Grande do Sul, enquanto nos estados do Maranhão e Pernambuco a proposta ainda se encontra em debate. Segundo Camini (2009, p. 154), contam-se atualmente: "37 escolas dessa modalidade, envolvendo aproximadamente 3.600 educandos e 350 educadores, em 37 acampamentos das áreas de reforma agrária".

A Escola Itinerante associada à luta pela reforma agrária é um enorme desafio, tanto para os sujeitos que a reivindicam, os trabalhadores sem-terra, quanto para o Estado, no que tange aos processos de reconhecimento da função social da terra. O movimento oriundo da relação social do capital, que tem por sujeitos os grandes proprietários de terras, empresários do agronegócio e banqueiros a eles associados, está organizado na União Democrática Ruralista (UDR) e na Confederação Nacional da Agricultura (CNA); conta com poderosos representantes no Congresso Nacional (MELO, 2006). A reação desse movimento é no sentido de impedir, de diferentes modos, o avanço da reforma agrária, feita em outros países e fundamentada no preceito constitucional de que a terra, um meio de produção que não resulta do trabalho, desempenha uma função social.

Esse desafio se manifesta mais concretamente na capacidade maior ou menor de controle sobre o MST e, no caso da educação do campo, por meio do formato de escola que o Estado pretende impor e ao qual esse Movimento se contrapõe. Para o MST, conforme Jaime Fogaça, na obra organizada por Meurer e David (2006, p. 66), sem a posse do "conhecimento sistematizado, os acampados não decifrarão os números apresentados sobre a reforma agrária nesse país. Sem a Escola, os acampados estão numa condição de excluídos também do exercício de ler o mundo".

Outro ponto de conflito refere-se à orientação pedagógica do MEC, por meio das secretarias de educação, quanto à avaliação para averiguar se o aluno reúne as condições de ser promovido ou não para a série seguinte. Na política adotada pelo MEC, a produtividade é o núcleo da avaliação escolar que incide exclusivamente sobre o domínio de competências em determinados conteúdos programáticos. Já na proposta peda- 
gógica do MST, “percebe-se um esforço de fazer da avaliação uma prática dialógica, processual e emancipatória, que envolve o conjunto da comunidade", como afirma Isabela Camini (2009, p. 175). Tendo por referência o método inspirado na pedagogia do educador brasileiro Paulo Freire, a proposta pedagógica da Escola Itinerante parte das questões práticas tomadas como vivências geradoras, desenvolvendo o trabalho pedagógico de forma a estabelecer uma relação entre as diferentes áreas do conhecimento com aquelas questões incrustadas na realidade vivida no cotidiano dos acampamentos.

Essa escola, na sua itinerância, pode sobreviver aos ataques e aos despejos, sendo reconstruída pela comunidade dos pais, educadores e educandos, registra Farias (2008, p. 61), porque ela se "faz debaixo das árvores, na beira de uma estrada, de um rio, nas ruas, nas ocupações de terra, pedágios, na roça. Ela se faz, ainda, nas situações de despejo promovido pelo próprio Estado, que a aprovou para funcionar desta forma itinerante", afirmam Grein e Gehrke (2008, p. 87). A permanência na luta pela desapropriação de determinada área de terra, que responda às características estabelecidas pela legislação vigente para se fazer a reforma agrária, determina a configuração do acampamento e da escola como provisória. Desse modo, mesmo admitida na estrutura legal do Estado, essa escola contribui para transformar "a espontaneidade das ações dos sem-terra em formas concretas e conscientes de luta de classe", como reconhece o educador Charles Luciano (2008, p. 107).

Ainda que a proposta pedagógica de Escola Itinerante esteja em confronto com o formato que toma a escola liberal (CAMINI, 2009), ela apresenta contradições peculiares ao modo de produção capitalista em que está inserida. Essas contradições têm sido confirmadas em experiências efetuadas em Santa Catarina, no Paraná e no Rio Grande do Sul. Pesquisadores vinculados à Universidade Federal de Santa Catarina (UFSC) (BELTRAME e outros, 2009, p. 97), ao analisarem a experiência da Escola Itinerante de Lages/SC, deixam em dúvida se esta poderia ser considerada "uma escola itinerante ou estaria mais próxima de uma escola nucleada" "1? No Paraná, Grein e Gehrke (2008, p. 101) registram que, no "período de 2004 a 2008, foram atendidos aproximadamente a 7.636 alunos distribuídos em 446 turmas, compreendendo os níveis de Educação Infantil, Ensino Fundamental ( $1^{\mathrm{a}}$ a $4^{\mathrm{a}}$ e $5^{\mathrm{a}}$ a $8^{\mathrm{a}}$ séries $)$ e Ensino Médio". Todavia, o apoio do governo desse estado/PR também deixa 
espaço para a dúvida sobre se, de fato, as escolas itinerantes podem significar o "novo" ou apenas garantem, com o reconhecimento do Estado, a escolarização de crianças, jovens e adultos acampados. Isso porque, no Paraná, as escolas do campo, nas quais se incluem as itinerantes, se encontram em situação bastante precária quanto ao trabalho docente, às instalações físicas, aos materiais didáticos, equipamentos e biblioteca.

Tendo pesquisado a realidade da Escola Itinerante no estado/RS, Luciano (2008, p. 101) registra essas contradições ao reconhecer que, quanto mais o Setor de Educação do MST se submete às exigências do Estado, deixando em segundo plano os princípios educativos do Movimento, tanto menos necessários se tornam a coerção e o controle sobre suas experiências pedagógicas. Portanto, é assumindo a sua condição de classe e como um movimento coletivo de luta pelo cumprimento da função social da terra que o Movimento Camponês, na figura do MST, é criticado e perseguido, o que vem ocorrendo no Rio Grande do Sul desde 2008.

Mesmo tendo sido o pioneiro na legalização da Escola Itinerante, conforme visto anteriormente, no estado/RS ela é objeto de perseguição, como comprova a Ata do Conselho Superior do Ministério Público do Estado do Rio Grande do Sul, de 10 de dezembro de 2007. Nela encontra-se registrado que podem ser tomadas medidas e até proceder-se ao "ajuizamento de ações civis públicas com vista à proteção da infância e juventude em relação às bases pedagógicas veiculadas nas escolas mantidas ou geridas pelo MST, nitidamente contrárias aos princípios contidos na Constituição Federal e que embasam o Estado Democrático de Direito". Tendo como justificativa essa decisão legal do Ministério Público, a Secretaria de Educação (SE/RS) procedeu ao fechamento das escolas itinerantes do MST e, sem ouvir os pais, os educadores, os educandos e a comunidade acampada, removeu cerca de 500 crianças para escolas-polo nas sedes dos municípios.

O promotor de justiça Gilberto Thums, que assinou a Ata de $10 / 12 / 2007$, anteriormente referida, foi entrevistado por Alexandre Oltramari, da Revista Veja (22/04/2009, p. 64-65). Nessa reportagem, o jornalista afirma que o mencionado promotor contabiliza oito vitórias contra o MST. Considera, entre essas vitórias, o fato de ter convencido "O governo gaúcho a colocar na clandestinidade as escolas itinerantes do MST - versão sem terra das escolas muçulmanas, conhecidas como 
madraçais, que fabricam terroristas dispostos a dar a vida em nome do Islã" (OLTRAMARI, 2009, p. 64). Dando ênfase à ação dirigida às escolas itinerantes, o jornalista afirma que estas, "colocadas na clandestinidade pela ação do promotor, são o laboratório no qual o movimento configura suas crianças para a guerra" (OLTRAMARI, 2009, p. 65). A reportagem retrata, com muita propriedade, a visão que os meios de comunicação passam a respeito da escola do campo, vinculada às ações que visam a tirar a reforma agrária do texto constitucional para aplicá-la à realidade dos trabalhadores sem-terra.

Conforme visto até aqui, embora de maneira bastante sucinta, do mesmo modo que o Movimento Camponês tem garantido conquistas no âmbito da educação do campo, este enfrenta enormes desafios, principalmente no caso das escolas itinerantes, tendo em vista que, na luta pela escola, está implícita a luta pela terra que garanta trabalho e vida digna aos agricultores. Esses desafios remetem às contradições próprias da relação entre trabalho e capital, em que neste está implícita a propriedade privada da terra, entendida hoje como reserva de valor. Nessa relação social, em que se sustenta a estrutura do Estado liberal, uma reforma agrária, mesmo dentro da lei, "atua, em relação ao desenvolvimento, na contra-lógica do projeto historicamente implementado e financiado em nosso país" (HACKBART; SANTOS, 2009, p. 8). Assim, com o sentido de dar prosseguimento à demonstração da hipótese inicial, será abordada, no item seguinte, a questão do PRONERA, seu significado para a formação humana pretendida pelo Movimento Camponês e os entraves que lhe são colocados pelas organizações que representam os grandes proprietários e empresários do agronegócio associados ao capital financeiro.

\section{PRONERA para quem: uma esperança ou uma ameaça?}

O PRONERA é o resultado de uma longa trajetória dos movimentos sociais populares que lutam por reforma agrária, no Brasil, e para os quais a função social da terra, confirmada pela Constituição Federal de 1988, está associada ao trabalho para uma sobrevivência digna, portanto, com acesso à educação em todos os níveis. Dois eventos, já mencionados, marcam o deslanchar dessa caminhada: a realização do ENERA, em 1997, e a Conferência Por uma Educação Básica do Campo, em 1998. Esses 
eventos, para os quais contribuíram organizações sociais como a CPT, a UNESCO e o UNICEF, também contaram com a participação de pesquisadores vinculados a universidades públicas e comunitárias. As preocupações dos pesquisadores se voltavam para os altos índices de analfabetismo e os baixos níveis de escolarização dos jovens e adultos assentados. Como a preferência do MEC era pela política de reforço ao ensino regular, o PRONERA, criado por meio da Portaria n. 10, de 16/04/1998, ficou subordinado ao Ministério Extraordinário de Política Fundiária. Somente em 2001, pela Portaria n. 837, o PRONERA é incorporado ao INCRA. Em 2004, adequando-se às diretrizes políticas do governo de Luiz Inácio Lula da Silva, o Manual de Operações do PRONERA é aprovado pela Portaria INCRA, n. 282 de 16/04/2004, tendo a formação em nível superior como uma de suas linhas de ação. Assim, "a criação do PRONERA foi o elemento de relevância para inserir a educação na agenda da reforma agrária" (MOLINA, 2004, p. 79).

Em 1998, foram encaminhados projetos provenientes de 38 instituições de ensino superior ao PRONERA, para serem avaliados, "abrangendo 23 estados, com a meta de alfabetizar 100 mil alunos e formar 5 mil monitores e 500 coordenadores locais, envolvendo 100 professores universitários e 500 estudantes." (ANDRADE; DI PIERRO, 2004, p. 24). Na página da Universidade Federal Rural da Amazônia (UFRA) aparece a afirmação de que, na atualidade, 45 instituições de ensino superior, entre federais, estaduais e institutos tecnológicos, participam das ações do PRONERA referentes à oferta de ensino tecnológico, de graduação e pósgraduação aos integrantes dos movimentos sociais populares do campo ${ }^{12}$.

Do mesmo modo, a página do TRAMSE ${ }^{13}$ confirma a participação de universidades, secretarias de educação e escolas federais de ensino médio, através do PRONERA, com apoio do INCRA, para desenvolver "uma ação conjunta visando o desenvolvimento dos assentamentos, tomando-se como base a educação". Na página do MDA, consultando-se sobre o INCRA, no qual está sediado o PRONERA, registra-se que este "tem o objetivo de ampliar os níveis de escolarização formal dos trabalhadores rurais assentados". E, entre suas ações, destacam-se "a escolarização de assentados rurais, a profissionalização em nível médio e técnico e também em nível superior"14.

O PRONERA destina-se aos agricultores assentados do INCRA e do MST, mas também contribui para projetos de educação do campo 
voltados para agricultores familiares, como é possível confirmar nas experiências realizadas com o MSTTR, as federações de trabalhadores rurais, a CONTAG, a Rede de Educação do Semiárido Brasileiro (RESAB) e os Centros Familiares de Formação por Alternância (CEFFA) (LUNAS; ROCHA, 2009). Antes de adentrar pela análise da proibição do funcionamento do PRONERA, registra-se que este se respalda na Resolução CNE/CEB n. 1/2002, no que esta afirma sobre o financiamento da educação do campo como um dever do Estado, mobilizando, para isso, os dispositivos constitucionais e os previstos na Lei de Diretrizes e Bases da Educação Nacional - LDB 9.394/96.

Os problemas enfrentados pelo PRONERA começam com o Acórdão 2.653/2008, do Tribunal de Contas da União - TCU, que proíbe o pagamento de bolsas aos professores que são funcionários públicos. Também o MEC se manifestou proibindo o pagamento de bolsas aos alunos, justificando não haver legislação que as autorizasse. Além da proibição do pagamento de bolsas, o TCU passou a exigir que o INCRA, a autarquia que repassa os recursos ao PRONERA, "ao invés de firmar convênios com as universidades faça licitação para oferecer os cursos de alfabetização até a pós-graduação" (http://www.excola.com.br, consulta em 08/09/2010).

Diz-se que iniciativa do TCU foi motivada pela denúncia de um aluno do curso de Agronomia da Universidade do Estado do Mato Grosso (UNEMAT), segundo o qual "grande parte do orçamento do PRONERA era repassada ao Movimento dos Trabalhadores Sem Terra" (mesma fonte citada). $\mathrm{E}$ na página do INCRA (http://www.mda.gov.br/incra, consulta 09/09/2010), está registrado que, além da exigência de licitação para a efetivação dos projetos, também constava, no mesmo Acórdão 2.653/2008 do TCU, "a determinação que inibia por completo a participação dos movimentos sociais durante o planejamento, execução e acompanhamento do Programa”.

Antes de entrar na análise do que indicamos como reação do Estado, por meio do Acórdão do TCU, há necessidade de acrescentar que os projetos encaminhados ao PRONERA/INCRA, no que tange à utilização dos recursos, têm de ser avaliados pelo Conselho Nacional de Desenvolvimento Rural Sustentável (CNDRS), um órgão colegiado que integra a estrutura do MDA. Isso porque o financiamento sustenta-se na arrecadação de $2,7 \%$ da contribuição básica sobre a folha de pagamento 
das agroindústrias, incluindo cooperativas rurais (GRABOWSKI, $2010)^{15}$.

De posse dos elementos essenciais de identificação do PRONERA, três questões se destacam nessa interferência do TCU sobre a efetivação desse Programa vinculado ao INCRA. A primeira refere-se à materialidade do programa; diz respeito, nesse caso, à arrecadação dos recursos efetuada como contribuição da folha de pagamento de agroindústrias e cooperativas para o financiamento dos projetos do PRONERA. Observa-se, nesse caso, uma semelhança com a base financeira do chamado Sistema "S", que se sustenta pela arrecadação de recursos, por parte do Estado, portanto públicos, mas cuja gestão é de caráter privado, excluindo o controle público sobre a sua utilização e incluindo a cobrança dos alunos que efetuam os $\operatorname{cursos}^{16}$. Então: será que as agroindústrias e cooperativas não estariam pretendendo obter o mesmo controle sobre os recursos repassados ao PRONERA, pelo INCRA, eliminando a participação dos movimentos sociais populares e oferecendo cursos na modalidade dos que funcionam pelo Sistema "S"?

A segunda questão refere-se à exigência de que os projetos encaminhados ao PRONERA sejam objeto de licitação, traduzindo a abertura para as parcerias público-privadas. Essas parcerias podem significar rendimentos extras às empresas que se capacitarem no processo de licitação. Sobre isso, de acordo com os projetos desenvolvidos pelas universidades, um aluno do curso de graduação em Agronomia, através do PRONERA, custa ao INCRA a importância de R \$4.500,00 ao ano. Já o aluno que não faz a sua graduação pelo PRONERA pode custar o dobro desse valor. "Nós queremos garantir a continuidade do programa, o material didático e o transporte. Não podemos abrir uma licitação e tratar a educação como uma mercadoria", afirma Adelaide Coutinho, da Universidade Federal do Maranhão (UFMA), na audiência pública aos pesquisadores e reitores com representantes do TCU, em 17/09/2010 ${ }^{17}$.

A terceira questão refere-se à proibição de os movimentos sociais populares, envolvidos com a educação do campo, atuarem no planejamento, no acompanhamento e na execução do Programa, o que também foi efeito daquela denúncia. Há, nessa terceira questão, a evidência de que tanto a escola quanto a universidade sejam espaços de produção do conhecimento. Portanto, não é de se estranhar que haja disputa entre os representantes do capital e os representantes do trabal- 
ho, que, neste caso, são os trabalhadores do/no campo, organizados no Movimento Camponês. O conhecimento novo é hoje, reconhecidamente, uma força produtiva, por isso, um objeto de acirrada disputa, inclusive entre empresas concorrentes.

No mesmo encontro dos reitores com o TCU, também se pronunciou Mônica Molina, da UnB, afirmando que: "Muito mais que contribuir para as comunidades que precisam do programa, os jovens da cidade que, de alguma forma, entram em contato com a vida no campo, conhecem outra realidade. São alunos que se tornam outros cidadãos, com outra visão de mundo". Também, sobre isso, fez uso da palavra Clarice dos Santos, Coordenadora Geral da Educação do Campo e Cidadania do INCRA, no mesmo evento. Disse que o direito à participação dos movimentos sociais no PRONERA está respaldado pela "Constituição Federal e pela legislação educacional. O PRONERA é justamente uma conquista dos movimentos sociais" "18. Acrescente-se que o Ministro Ubiratan Aguiar, Presidente do TCU, apenas recebeu a comitiva que solicitara a audiência, deixando a recepção a cargo de Júnios Marques, da Secretaria de Recursos do TCU. Mas não podemos pressupor, com isso, que o Ministro não tenha dado a devida importância à presença dos representantes das universidades, da CONTAG e do MST que lá estiveram.

Dando continuidade à análise, cabe à Secretaria de Recursos do TCU dar o parecer técnico sobre a solicitação das universidades e dos movimentos sociais populares do campo, representados, na ocasião, por José Wilson Souza Gonçalves, Secretário de Política Social da CONTAG, e Edgar Kolling, Coordenador do Setor de Educação do MST. A decisão final ainda não tem data para ser divulgada, foi a resposta do anfitrião. Em paralelo à tentativa de extinção do PRONERA ou de orientá-lo para os interesses das empresas do agronegócio, desenrola-se no Congresso Nacional a Comissão Parlamentar Mista de Inquérito (CPMI) contra a reforma agrária, mobilizada pelos "setores conservadores liderados por Kátia Abreu (DEM-TO) e Onyx Lorenzoni (DEM/RS)"19. Cabe lembrar que "os altos índices de concentração fundiária guardam intrínseca relação com a forma como se dá a utilização das terras no Brasil” (MOLINA, 2004, p. 64). Isso explica por que os parlamentares que representam o latifúndio e o agronegócio exigem a investigação das entidades sociais que atuam nos assentamentos de reforma agrária. E, mesmo sem estarem presentes 
à maioria das sessões, insistem para que seja prorrogada a CPMI, cujos resultados foram favoráveis à manutenção dos convênios estabelecidos com o PRONERA.

Embora sucinta, a análise permite captar o embate entre os movimentos sociais do campo constituintes da unidade Movimento Camponês e os setores representativos dos interesses do capital agroindustrial, associado ao capital financeiro, cujos sujeitos concretos são grandes proprietários de terras e ocupam posições estratégicas na estrutura do Estado. Nesse sentido, o Programa Escola Ativa, adotado pelo MEC como uma política de Estado, pode ser interpretado, conforme nossa hipótese de trabalho, na perspectiva de uma reação que atinge o Movimento Camponês pela base, ou seja, na formação das crianças que estão nas escolas rurais multisseriadas. Vamos aprofundar essa discussão no item seguinte.

\section{O Programa Escola Ativa em confronto com a Educação do Campo}

O Programa Escola Ativa foi implementado por meio do Fundo de Desenvolvimento da Escola (Fundescola), também um Programa resultante de acordo entre o Banco Mundial (BM) e o MEC, para ser desenvolvido através de secretarias estaduais e municipais de educação. A missão que cabia a esse Ministério, ao implementar o Programa Escola Ativa com o apoio financeiro do BM, era intervir nos processos de gestão escolar, visando "à melhoria da qualidade das escolas do ensino fundamental e à permanência das crianças nas escolas públicas, nas regiões Norte, Nordeste e Centro-Oeste" (OLIVEIRA; FONSECA; TOSCHI, 2005, p. 128). Com exceção dos pesquisadores João de Oliveira, da Universidade Federal de Goiás, Marília Fonseca, da Universidade de Brasília, e Mirza Toschi, da Universidade do Estado de Goiás, autores de uma pesquisa da qual resulta a citação acima, há poucos estudos sobre os resultados do Programa Fundescola, em que se inclui o Programa Escola Ativa, aplicado no Brasil.

Tendo claros esses limites, parte-se para a definição da proposta metodológica identificada como Escola Ativa, voltada para as classes multisseriadas do ensino fundamental existentes nas áreas rurais. Essa definição é formulada por Fernando Piza, coordenador, e Lilian Sena, 
assessora técnica do Programa do mesmo nome, ambos vinculados também ao Programa Fundescola ${ }^{20}$. Para esses autores, é preciso combinar "na sala de aula uma série de elementos e instrumentos de caráter pedagógico/administrativo, cuja implementação objetiva aumentar a qualidade do ensino oferecido naquelas classes". Com essa finalidade, as concepções que sustentam o referido programa podem ser sintetizadas em um princípio, o da aprendizagem ativa, centrada no aluno.

Gustavo Gonçalves, em estudo produzido em 2006²1, confirma que o Programa Escola Ativa é inspirado no Programa "Escuela Nueva", que já fora aplicado na Colômbia entre os anos de 1970/80 e avaliado por Rosa Maria Torres ${ }^{22}$. Aquele pesquisador enumera as estratégias metodológicas adotadas para as classes multisseriadas rurais que aparecem, também, no texto daqueles funcionários do Fundescola, anteriormente referidos. São elas: aprendizagem ativa centrada no aluno em sua realidade social; o professor como estimulador e facilitador da aprendizagem; aprendizagem cooperativa; gestão participativa; avaliação contínua e processual; promoção flexível. Destaca-se que, além da Colômbia, o Programa Escola Ativa também foi adotado em outros países latino-americanos, como Argentina, Chile, Costa Rica, Equador, Guiana, Guatemala, Honduras, Paraguai, Peru e República Dominicana, conforme o documento Escola Ativa: Capacitação de Professores, do MEC, lançado em 1999 (ARAÚJO; RIBEIRO, 2007).

Retomando o que foi afirmado no início, tem-se que o foco do Programa Escola Ativa, voltado à elaboração e ao acompanhamento do Plano de Desenvolvimento da Escola (PDE), é a gestão escolar associada à corresponsabilidade. Sua meta é atingir uma autonomia "descentralizadora, por meio de um fundo repassado à escola, com vistas a estimular o quadro administrativo a tomar decisões que afetem materialmente a escola, e a responsabilizar-se pelos resultados de suas decisões" (OLIVEIRA; FONSECA; TOSCHI, 2005, p. 129). No entanto, a pesquisa feita pelos mesmos autores em documentos do referido Programa mostra que a concepção de gestão escolar não coincide ou, pelo contrário, afasta-se do caráter democrático proposto pela legislação brasileira, principalmente no que diz respeito à LDB 9.394/96. Aproxima-se, isso $\operatorname{sim}$, do que se entende como gestão racional, assentada sobre ferramentas de gestão, atributos gerenciais e treinamento de pessoal, uma tendência denunciada por Saviani (2007) 
como indício da retomada do tecnicismo dos anos de 1970, porém sob uma nova roupagem.

Xavier $\mathrm{Neto}^{23}$, pesquisador vinculado à Universidade do Estado do Rio Grande do Norte, também investiga a aplicação do Programa Escola Ativa nesse estado/RN. Seu objetivo, no trabalho consultado, é confrontar a proposta pedagógica do MST, que identifica como integrada a um projeto histórico socialista, e o Projeto Escola Ativa, vinculado ao Banco Mundial e integrado a um projeto histórico capitalista. Afirma que, enquanto a proposta do MST respalda-se na concepção de educação formulada nas obras de Pistrak, Makarenko e Vigotsky, e, no Brasil, em autores como Paulo Freire, Miguel Arroyo e Roseli Caldart, no Programa Escola Ativa observa-se uma mistura de autores como Freinet, Vigotsky, Piaget, Freire e Emília Ferreiro. Incluindo uma reinterpretação despolitizada das obras de Freire e Vigotsky, os demais autores podem ser identificados com uma concepção liberal, revisada e renovada, que corresponde à escola nova.

$\mathrm{Na}$ pesquisa efetuada pelo autor naquele estado/RN, quando da aplicação do Programa Escola Ativa, Xavier Neto observa que são utilizados recursos pedagógicos da formação pedagógica efetuada na Colômbia, quando da aplicação do Programa "Escuela Nueva", como já afirmara Gonçalves no seu projeto de pesquisa ${ }^{24}$. Portanto, esses recursos não seriam adequados à realidade brasileira. No mesmo estudo, Xavier Neto (2007, nota n. 40) registra dificuldades enfrentadas quando da aplicação do Programa Escola Ativa, que, de acordo com o autor, não poderiam ser explicitadas apelando-se para interpretações de educação moderna ou antiga. No seu artigo, e tendo por referência o Encontro Nacional de Capacitação, dentro do Programa Escola Ativa do $\mathrm{MEC}^{25}$, afirma Xavier Neto (2007, p. 3): "o que existe é um choque de concepções entre a realidade da educação do campo e a teoria ministrada nos cursos de capacitação".

Confirmando essa declaração do autor, Oliveira, Fonseca e Toschi (2005), na pesquisa já referida, declaram ser evidente a existência, dentro do MEC, de concepções teóricas antagônicas de gestão educacional, registrando que uma delas teria "um caráter burocrático que internaliza modelos concebidos por agências financeiras internacionais". A outra expressa "a aspiração da comunidade educativa por uma escola mais autônoma e de qualidade...", na qual se insere a proposta 
político-pedagógica da educação do campo (OLIVEIRA; FONSECA; TOSCHI, 2005, p. 143).

Jacqueline Freire, pesquisadora da Universidade Federal do Pará (UFPA) e integrante do Grupo de Estudo e Pesquisa em Educação do Campo na Amazônia (GEPERUAZ), também desenvolveu estudos sobre o Projeto Escola Ativa, implementado no estado/PA ${ }^{26}$, a partir de 1999. Em artigo publicado numa coletânea organizada por Hage (2005), Jacqueline Freire também aponta como fonte inspiradora a experiência colombiana, dizendo que esta se expandiu por diversos países da América Latina, entre os quais o Brasil. Para essa autora, na realidade do Pará, elegeu-se como prioridade a questão metodológica para explicar os baixos índices de rendimento e de eficácia dos processos pedagógicos, principalmente as metodologias tradicionais voltadas mais à memorização do que à compreensão dos conteúdos trabalhados em sala de aula.

Porém, a autora problematiza a perspectiva da escola ativa, uma reedição da escola nova, apontada como referência teórico-metodológica para a educação, rumo ao século XXI. Contraditoriamente ao divulgado nos documentos oficiais, o paradigma proposto "reflete a concepção do 'otimismo pedagógico' das décadas de 1920 e 30" (FREIRE, 2005, p. 200), ou, mais do que isso, desenterra uma concepção produzida em época passada em resposta a outros desafios. Confirmando esta leitura, segundo a autora, os eixos pedagógicos e os pressupostos que os sustentam apontam para um retorno ao escolanovismo de John Dewey, porém descontextualizado do momento histórico em que foi produzido e das questões para as quais esse filósofo buscava encontrar soluções. Uma análise dos módulos de aprendizagem referenda o afirmado de que os processos educativos estão centrados no aluno, visando à sua participação ativa no processo de ensino-aprendizagem. Embora isso possa significar um avanço, "O Projeto Escola Ativa, ao exacerbar fundamentos psicopedagógicos e prescrições pedagógicas coloniza, fetichiza e coisifica o currículo ativo, refreando práticas curriculares que efetivamente contribuam para a emancipação humana" (FREIRE, 2005, p. 205).

Acentuando sua crítica, Jacqueline Freire aponta que o Programa Escola Ativa pode ser compreendido no contexto de reforma educacional dos anos de 1990, durante o governo do Presidente Fernando Henrique Cardoso. "Sob a égide do neoliberalismo, e engendrada pelo processo de globalização, as reformas educacionais no país constituíram- 
se em um imperativo na agenda governamental, na perspectiva de promover a 'modernização' dos sistemas escolares,...” (FREIRE, 2005, p. 267). É interessante registrar que esse mesmo Programa Escola Ativa teve continuidade como política do MEC, em 2008, após a conquista da educação do campo, durante o governo do presidente Luiz Inácio Lula da Silva, que, pelo menos aparentemente, teria um viés popular tendo em vista o Partido dos Trabalhadores (PT), pelo qual foi eleito.

Outro estudo da aplicação do Programa Escola Ativa em escolas multisseriadas existentes nas áreas rurais foi feito no município de Várzea Grande, no estado do Mato Grosso (ARAÚJO: RIBEIRO, 2007). Nele, as autoras retomam o contexto histórico da década de 1990, no interior do qual, paralela à iniciativa de aplicação daquele Programa, sobressaem pressões provenientes dos movimentos sociais populares do campo. Esses movimentos reivindicam políticas de educação que respondam aos seus interesses de trabalho, à sua cultura e à necessidade de condições para a sua permanência na terra. É nesse mesmo processo, conforme analisado anteriormente, que se constrói uma concepção/prática de educação do campo associada às demandas históricas daquele Movimento.

Portanto, causa estranheza que, em plenos anos de 1990, estando o Movimento Camponês organizado e apresentando uma proposta de educação do campo, seja implementado o Programa Escola Ativa para as escolas rurais multisseriadas das regiões Norte, Nordeste e Centro-Oeste, uma retomada dos "princípios e fundamentos do ideário escolanovista de 1930”. A diferença é que, “desta vez não mais para toda a rede de ensino e sim para as escolas do meio rural" (ARAÚJO; RIBEIRO, 2007, p. 270), o que, de novo, parece mais estranho, ainda... $\mathrm{Na}$ análise da proposta pedagógica do mesmo Programa, as autoras confirmam o que já dissera Jacqueline Freire, ou seja, que: "Nesta proposta está contida a pretensão de estabelecer um novo paradigma educacional para o século XXI, delegando às escolas a tarefa de elaborar e executar sua proposta pedagógica" (ARAÚJO: RIBEIRO, 2007, p. 267), Esqueceram-se os técnicos do MEC de mencionar que esse paradigma pode ter uma feição de defunto, enterrado na metade do século $\mathrm{XX}$ por não dar conta das questões que se propunha.

A análise que contrapõe as escolas itinerantes e o PRONERA, como iniciativas dos movimentos sociais populares integrantes do Movimento Camponês, ao Programa Escola Ativa, como política do 
MEC, confirma a hipótese colocada de início. Trata-se de uma reação do Estado burguês ao avanço do Movimento Camponês, através da substituição gradativa da educação do campo pelo Programa Escola Ativa para escolas multisseriadas rurais, atingindo, desse modo, a formação humana na sua base. Com isso, poderão ficar mais explícitas as contradições que atravessam o embate entre o Estado brasileiro e o Movimento Camponês, no que tange à educação do campo.

\section{Algumas conclusões que podem ser ampliadas}

Os autores analisados e os materiais consultados na página do MEC, na internet (http:/ / www.mec.gov.br; redecomunicadores.mec.gov.br; portal.mec.gov.br/secad/) em diversas ocasiões (2008/2009/2010), sobre a educação do campo e sobre o Programa Escola Ativa, deixam evidente que, de fato, está ocorrendo um embate de práticas/concepções de educação. De um lado, coloca-se a educação do campo que vem sendo construída no processo de luta e ocupação da terra de trabalho e é retomada nos anos de 1970, ainda durante a ditadura militar. Essa concepção vai sendo sistematizada no interior dos movimentos sociais populares, particularmente, a partir de uma prática social do Movimento Camponês, portanto, não está pronta. Com isso, assume a dimensão de ser coletiva, estar em movimento, abrir-se à escuta de novas contribuições, de estar atenta ao trabalho e às necessidades que este coloca em relação a uma vida digna para as famílias camponesas. Mas, como é possível observar, do mesmo modo que os trabalhadores enfrentam a criminalização de suas organizações sociais e a dificuldade de o Estado colocar em prática a função social da terra, definida constitucionalmente, também as suas propostas pedagógicas, como a Escola Itinerante, em casos como o do estado do Rio Grande do Sul, são impedidas de funcionar.

De igual maneira ao que é feito com a Escola Itinerante, colocam-se empecilhos à materialização dos projetos de educação do campo, pela imposição de substituir os convênios por licitações e parcerias, pela proibição de os movimentos populares participarem da elaboração e da execução dos projetos educativos, e pela pressão para exercer controle privado sobre recursos públicos do INCRA destinados ao PRONERA. E sabemos que, sem esses recursos, tendo em vista a pobreza dos trabalha- 
dores organizados nos movimentos sociais populares e a condição das instituições públicas, implodem-se os alicerces indispensáveis à construção de uma estrutura que permita ao Movimento Camponês realizar seu projeto de formação humana em trabalho agrícola-educação escolar.

De outro lado, reedita-se uma concepção da primeira metade do século XX, um período de desenvolvimento industrial combinado com processos de urbanização, quando estava forte o Movimento Operário; uma concepção forjada, portanto, em resposta a conflitos sociais que, em alguns casos, culminaram com processos revolucionários. Por que essa concepção que, pelo menos no Brasil, recebeu tantas críticas ao ser proposta para a educação pública, demandada pela industrialização associada ao aumento das populações urbanas ${ }^{27}$, foi retirada do museu da história? Por que uma concepção civilizatória, urbana e eurocêntrica é retomada em um momento de organização do Movimento Camponês, que busca a reforma agrária e enfrenta o poder econômico do agronegócio e dos grandes proprietários de terras e bancos a eles associados, no Brasil? Por que foi imposta de fora, associada a empréstimo de recursos por parte de um organismo internacional, como o Banco Mundial?

Essas questões se acentuam quando se consulta uma obra mais recente, História das Ideias Pedagógicas no Brasil, de Dermeval Saviani, publicada em 2007, em que o pesquisador aponta para uma retomada de concepções próprias da Escola Nova, porém assumindo uma nova feição. Trata-se de um neoescolanovismo, com ênfase no "aprender a aprender", em que o professor torna-se apenas um auxiliar do processo de aprendizagem, esvaziado da contrapartida do ensino, pois o essencial é que o aluno aprenda a fazer sozinho, adaptando-se, assim, à empregabilidade, na ausência de empregos para todos. Essa análise de Saviani encontra respaldo numa leitura do Relatório de Delors (2006) no qual aparece a exigência de "todos aprendermos a aprender" e de um ensino na perspectiva da equidade e não da igualdade. No campo, quem sabe, na ausência da terra de trabalho cuja função social está garantida na Constituição de 1988, mas o Estado brasileiro não a tem colocado em prática, também se apregoa o "aprender a aprender", a flexibilidade e a diversidade, quem sabe para a busca dos escassos empregos protegidos por direitos sociais ou mesmo o trabalho informal ou, ainda, terceirizado.

Não se tem respostas às indagações que brotam espontaneamente de uma realidade de embate entre a educação do campo e o Programa 
Escola Ativa, quando as escolas públicas urbanas e seus professores enfrentam tantos e tão graves problemas e não despertam a mesma atenção por parte dos poderes públicos. Parece, isso sim, que há necessidade de os pesquisadores e educadores estarem atentos a esse processo uma vez que, tanto na educação quanto na produção científica, estão implícitos princípios e projetos sociais determinados. No caso da autora deste artigo, a preocupação é que os trabalhadores e trabalhadoras, sejam urbanos ou rurais, tenham oportunidades de trabalho, de conquista e permanência na terra, de educação para si e os filhos, sobretudo, de condições para uma vida com dignidade. 


\section{Referências}

ANDRADE, Márcia; DI PIERRO, Maria Clara. A construção de uma política de educação na reforma agrária. In: ANDRADE, Márcia e outros (Org.). Educação na reforma agrária em perspectiva. Uma avaliação do Programa Nacional de Educação na Reforma Agrária. São Paulo: Ação Educativa; Brasília/DF: Pronera, 2004. p. 37-57.

ARAÚJO, Nilza; RIBEIRO, Marlene. Educação do campo em Mato Grosso: trabalho docente e a alfabetização em classes multisseriadas em Várzea Grande/MT. In: GRACINDO, Regina. (Org.) Educação como exercício de diversidade. Brasília: Líber Livro, 2007. v. 1, p. 259-279.

BELTRAME, Sonia et al. A Escola Itinerante de Lages. In: AUED, Bernadete. VENDRAMINI, Célia. Educação do campo: desafios teóricos e práticos. Florianópolis: Insular, 2009. p. 83-98.

BEZERRA NETO, Luiz. Sem-Terra aprende e ensina: estudo sobre as práticas educativas do movimento dos trabalhadores rurais. Campinas: Autores Associados, 1999.

BRASIL. Constituição da República Federativa do Brasil. Brasília: Centro Gráfico do Senado Federal, 1888. 292p.

BRASIL. MINISTÉRIO DA EDUCAÇÃO. Lei de Diretrizes e Bases da Educação Nacional n. 9.394 de 20/12/1996. In: SAVIANI, Dermeval. A Nova Lei da Educaşão. Campinas/SP: Autores Associados, 1997, p. 163-188.

BRASIL. CONGRESSO NACIONAL. Decreto-Lei n. 1.146 de 31/12/1970. Publicado no Diário Oficial da União de 31/12/1970.

BRASIL. TRIBUNAL DE CONTAS DA UNIÃO. Acórdão n. 2653/2008. Ata n. 29, de 20/08/2008. Publicado no Diário Oficial da União em 22/08/2008.

BRASIL. MINISTÉRIO EXTRAORDINÁRIO DE POLÍTICA FUNDIÁRIA. Portaria n. 10 de 16/04/1998. Criação do Programa Nacional de Educação na Reforma Agrária ${ }^{28}$.

CALAZANS, Maria Julieta. Para compreender a educação do Estado no meio rural. Traços de uma trajetória. In: THERRIEN, Jacques; DAMASCENO, Maria Nobre. Educação e escola no Campo. Campinas: Papirus, 1993. p. 15-42.

CAMINI, Isabela. Escola Itinerante nos acampamentos do MST: um contraponto ao projeto de escola capitalista? Porto Alegre: PPGEDU/UFRGS. 2007. Projeto de tese. 135p.

CAMINI, Isabela. Escola Itinerante na fronteira de uma nova escola. São Paulo: Expressão Popular, 2009.

CONFEDERAÇÃO NACIONAL DOS TRABALHADORES NA AGRICULTURA - CONTAG. Lei n. 4.504 de 30/11/1964. Questões Agrárias: Estatuto da Terra e direitos regulamentadores, Brasília, n. 8, nov. 1979, Série Documentos, 248p.

DAMASCENO, Maria Nobre; BESERRA, Bernadete. Estudos sobre educação rural no Brasil: estado da arte e perspectivas. Educação e Pesquisa, São Paulo, v. 30, n. 1. jan.-abr., 2004, p. 73-90.

DELORS, J. Educação: um tesouro a descobrir. Relatório para a UNESCO da Comissão Internacional sobre Educação para o século XXI. São Paulo: Cortez; Brasília: MEC, UNESCO, 2006.

GREIN, Maria. Izabel; GEHRKE, Marcos. Escola Itinerante no desafio da luta pela Reforma Agrária, em MST. Itinerante: Escola dos Sem Terra - Trajetórias e significados. 
Cadernos da Escola Itinerante: SEED/PR, Curitiba, v. 1, n. 2, out. 2008, p. 87-96.

FARIAS, Alcione. A trajetória de resistência da Escola Itinerante Ernesto Che Guevara, em MST. Itinerante: Escola dos Sem Terra - Trajetórias e significados. Cadernos da Escola Itinerante: SEED/PR, Curitiba, v. 1, n. 2, out. 2008, p. 43-64.

FOGAÇA, Jaime. Um caminho de muitas marcas: a luta dos sujeitos da Escola Itinerante do Rio Grande do Sul, em MEURER, Ane Carine; DAVID, Cesar. Espaços/tempos de Itinerância. Interlocução entre Universidade e Escola Itinerante do MST, Santa Maria/RS, Editoraufsm, 2006, p. 47-84.

FREIRE, Jacqueline. Currículo e docência em classes multisseriadas na Amazônia Paraense: O projeto escola ativa em foco. In: HAGE, Salomão (org.). Educação do Campo na Amazônia: retratos da realidade das Escolas Multisseriadas no Pará. Belém: Gráfica e Ed. Gutemberg, 2005. p. 196-211.

GOHN, Maria da Glória. História dos movimentos e lutas sociais. A construção da cidadania dos brasileiros. São Paulo: Loyola, 1995.

GOVERNO DO ESTADO DO RIO GRANDE DO SUL. CONSELHO ESTADUAL DE EDUCAÇÃO. Experiência Pedagógica - Escola Itinerante. Parecer n. 1313/1996. GRABOWSKI, Gabriel. Financiamento da educação profissional no Brasil. 197p. Tese (Doutorado em Educação) - Faculdade de Educação, Universidade Federal do Rio Grande do Sul, Porto Alegre, 2010.

GRITTI, Silvana. Educação rural e capitalismo. Passo Fundo/RS: UPF, 2003.

GUZMÁN, Eduardo Sevilla; MOLINA, Manuel González. Sobre a evolução do conceito de campesinato. São Paulo: Expressão Popular, 2005.

HACKBART, Rolf; SANTOS, Clarice. Dez anos de PRONERA e o Programa Residência Agrária. In: MOLINA, Mônica e outros (Org.). Educação do campo e formação profissional: a experiência do Programa Residência Agrária. Brasília: NEAD/MDA, 2009, p. 7-10.

HAGE, Salomão (org.). Educação do Campo na Amazônia: retratos da realidade das Escolas Multisseriadas no Pará. Belém: Gráfica e Ed. Gutemberg, 2005.

HEIJMANS, Rosemary Dore. Democratização da escola e o princípio da escola ativa. UNIrevista, [S.1.], v. 1, n. 2, abr. 2006, 14p. Disponível em:

<www.unirevista.unisinos.br>. Acesso em: 08 set. 2010.

KOLLING, Edgar; Ir. NERY - FSC, MOLINA, Mônica. Por uma Educação Básica do Campo. Brasília: Articulação por uma Educação Básica do Campo, 1999.

KOLLING, Edgar. Alternância e formação universitária. O MST e o curso de Pedagogia da Terra. UNEFAB. In: SOSSAI, Carlos Cristóvão e outros autores. Pedagogia da Alternância. Formação em alternância e desenvolvimento sustentável. Brasília: Cidade Gráfica. nov., p. 54-61, 2002.

LUCIANO, Charles. Escola Itinerante: uma análise das práticas educativas do MST no contexto da democracia liberal. Santa Cruz do Sul: Edunisc, 2008.

LUNAS, Alexandra da Costa; ROCHA, Eliene Novaes (Org.). Práticas Pedagógicas e Formação de Educadores (as) do Campo. Brasília: Dupligráfica, 2009.

MARTI, Jose. Educação em Nossa América. Textos selecionados por Streck, Danilo. Ijui: Unijui, 2007.

MELO, João Alfredo. (Org.). Reforma Agrária quando? CPI mostra as causas da luta pela terra no Brasil. Brasília: Gráfica do Senado, 2006. 
MEURER, Ane Carine; DAVID, Cesar. Espaços/tempos de Itinerância: interlocução entre Universidade e Escola Itinerante do MST. Santa Maria: Editoraufsm, 2006.

MOLINA, Mônica. O Pronera como construção prática e teórica da educação do campo. ANDRADE, Márcia e outros (Org.). Educação na reforma agrária em perspectiva. São Paulo: Ação Educativa; Brasília: Pronera, 2004, p. 61-88.

MORISSAWA, Mitsue. A história da luta pela terra e o MST. São Paulo: Expressão Popular, 2001.

MONARCHA, Carlos. A reinvenção da cidade e da multidão. São Paulo: Cortez/Autores Associados, 1990.

MST. Alternativas de Escolarização dos Adolescentes em Assentamentos e Acampamentos do MST. Cadernos do Iterra, Veranópolis, Iterra, v. 3, n. 8, nov. 2003.

NUNES, Clarice. Escola Nova no Brasil: do estado da arte à arte do estudo. In: GVIRTZ, S. (Org.) Escuela Nueva en Argentina y Brasil. Buenos Aires: Miño y Dávila, 1996, p. 13-39.

OLIVEIRA, João; FONSECA, Marília; TOSCHI, Mirza. O Programa Fundescola: concepções, objetivos, componentes e abrangência - a perspectiva de melhoria da gestão do sistema e das escolas públicas. Educação e Sociedade, São Paulo, Campinas, v. 26, n. 90, jan.abr. 2005, p. 127-148.

OLTRAMARI, Alexandre. Abatido pelo radicalismo. Revista Veja: Seção Brasil, São Paulo, n. 2109, abr. 2009, p. 64-65.

PILON, Jean-Marc. Le double défi du développement personnel et du développement local dans le cadre d'une formation universitaire. In: DEMOL, Jean-Noel; PILON, JeanMarc (Coord.). Alternance, développement local et personnel. Montréal: Éditions L'Harmattan, 1998. p. 151-164.

PINEAU, Gaston. Formações universitárias em alternância no Canadá e na França. UNEFAB. In: CALVÓ, Pedro Puig e outros autores. Pedagogia da Alternância. Formação em alternância e desenvolvimento sustentável. Brasília: Cidade Gráfica. p. 62-73, nov. 2002.

RIBEIRO, M. Movimento Camponês, Trabalho, Educação. Liberdade, autonomia, emancipação como princípios/fins da formação humana. São Paulo: Expressão Popular, 2010.

RIBEIRO, M. Trabalho-educação no Movimento Operário e no Movimento Camponês: unidade na diversidade. In: CANÁRIO, Rui; RUMMERT, Sonia. Mundos do Trabalbo e Aprendizagem. Lisboa: Educa, 2009. p. 119-132.

RIBEIRO, M. Escola Ativa para a educação do campo no Brasil: uma reedição da Escola Nova? In: CONGRESSO IBEROAMERICANO DE HISTÓRIA DA EDUCAÇÃO LATINO-AMERICANA, 9, 2009. Rio de Janeiro, UERJ, 2009, 10p.

SAVIANI, D. Escola e Democracia. São Paulo: Editores Associados, Cortez, 1983. (Coleção Polêmicas do Nosso Tempo, n. 5.)

SAVIANI, D. História das ideias pedagógicas no Brasil. Campinas/SP: Autores Associados, 2007.

SILVA, Lourdes Helena. As experiências de formação de jovens do campo: alternância ou alternâncias? Viçosa/MG: UFV, 2003.

SILVA, Maria do Socorro. Educação como direito: reler o passado, refletir o presente e projetar o futuro. In: LUNAS, Alexandra da Costa; ROCHA, Eliene Novaes (Org.). Práticas Pedagógicas e Formação de Educadores (as) do Campo. Brasília: Dupligráfica, 2009. p. 29-48. 
XAVIER NETO, Lauro Pires. Educação do campo em disputa: análise comparativa entre o MST e o Projeto Escola Ativa. SIMPÓSIO LUTAS SOCIAIS NA AMÉRICA LATINA, 1, 2007, Natal/RN. Natal: Universidade Federal do Rio Grande do Norte, 2007. 21p.

Páginas da internet (As datas dos acessos estão indicadas nas notas de rodapé).

Uso de expressões associadas para consulta: PRONERA, TCU, Programa Escola Ativa. http://webmail.ufra.edu.br/pipermail/docentes

http://www.excola.com.br

http://www.mda.gov.br/incra

http://.www.conversaafiada.com.br

http://www.tvebrasil.com.br/salto/boletins2001/cms/cmstxt3.htm

http://www.mec.gov.br

http://www.ced.ufsc.br/pronera/?page $=10$

http://www.fronesis.org 


\section{Notas}

1 O estudo é decorrente de pesquisas relacionadas ao projeto: Políticas para a educação rural/ do campo, no Brasil e no México: a repetição da história como tragédia ou como farsa? com o apoio do CNPq.

2 Agronegócio corresponde a uma articulação empresarial voltada à exportação envolvendo o setor de implementação de máquinas, a produção agrícola e a industrialização desta produção com o setor de distribuição e serviços. Essa cadeia articulada da produção, comércio e financiamento acaba por gerar uma quantidade pequena de postos de trabalho.

3 Pilon (1998), Kolling (2002), Pineau (2002) e Silva (2003) são autores que, entre outros, abordam a pedagogia da alternância.

4 No Brasil a Via Campesina congrega o Movimento dos Trabalhadores Rurais Sem Terra - MST, o Movimento dos Pequenos Agricultores - MPA, o Movimento dos Atingidos por Barragens - MAB, o Movimento das Mulheres Camponesas - MMC, a Pastoral da Juventude Rural - PJR, a Comissão Pastoral da Terra - CPT e a Federação dos Estudantes de Agronomia do Brasil - FEAB. (GUZMÁN; MOLINA, 2005, p. 1).

5 Integram esta Articulação as entidades: Conferência Nacional dos Bispos do Brasil CNBB; o Movimento dos Trabalhadores Rurais Sem Terra - MST; a Universidade de Brasília - UnB; a Organização das Nações Unidas para a Educação, Ciência e Cultura UNESCO; e o Fundo das Nações Unidas para a Infância - UNICEF (KOLLING, IR. NERY, MOLINA, 1999, p. 97-98).

6 A Via Campesina, movimento internacional que coordena organizações agrícolas, trabalhadores/as rurais e comunidades indígenas da Ásia, da África, das Américas e da Europa, teve origem na Bélgica, em 1993. (CAMINI, 2007, nota n. 8, p. 9).

7 Esta Confederação surge em 1963, de um acordo entre a Igreja católica, que desenvolvia trabalhos de pastoral junto a sindicatos de trabalhadores rurais, e o Partido Comunista Brasileiro - PCB, que exercia influência sobre a União dos Lavradores e Trabalhadores Agrícolas Brasileiros - ULTAB (MORISSAWA, 2001).

8 A Constituição da República Federativa do Brasil de 1988 retoma, do Estatuto da Terra (Lei 4.504 de 30/11/1964), a "função social da propriedade", definida no Título VII, Da Ordem Econômica e Financeira, no Cap. III - da Política Agrícola e Fundiária e de Reforma Agrária, nos artigos n. 184 e 186. Sobre Estatuto da Terra, ver CONTAG (1979).

9 Ver a nota n. 51, da obra de I. Camini (2009, p. 101), que diz: "Como Escola Intinerante aparece em J. MARTI, "Mestres itinerantes", integrando os textos sobre educação, na obra do mesmo autor, Educação em Nossa América, 2007”.

10 Ver CAMINI, 2009, p. 117.

11 Escola-núcleo ou escola-polo corresponde a uma iniciativa do Estado brasileiro para reduzir custos com a educação das populações rurais, adotando a política de extinção de escolas unidocentes ou multisseriadas e transferindo os estudantes para uma escola maior, situada na sede do município. Com isso, as crianças e jovens passam a receber 
uma formação marcada não só pelo conteúdo, mas também pelo espaço e pela cultura urbanos. Para chegar às escolas, alunos e professores precisam ser transportados por meio de ônibus trafegando por estradas de chão batido ou, no caso da Região Norte, por meio de barcos, o que, muitas vezes, coloca em risco suas vidas.

12 Foi consultada a página http://webmail.ufra.edu.br/pipermail/docentes da PróReitoria de Extensão da Universidade Federal Rural da Amazônia em 09/09/2010, sobre o PRONERA.

13 tramseufrn.blogspot.com/ Blog da Universidade Federal do Rio Grande do Norte. Acesso em 09/09/2010. A sigla TRAMSE, do blog, que, por extenso, é Trabalho, Reforma Agrária, Movimentos Sociais e Educação do Campo, é a mesma, ou seja, TRAMSE, adotada pelo Grupo de Pesquisa Trabalho, Movimentos Sociais e Educação, do Programa de Pós-Graduação da Universidade Federal do Rio Grande do Sul, existente desde 2000.

14 http://www.mda.gov.br/incra, acesso em 03/08/2009. A página aparece como www.incra.gov.br

15 Esta contribuição está prevista no Art. $2^{\circ}$ do Decreto-Lei n. 1.146/1970 - FPAS 531, 795, 825; na mesma Lei está prevista a contribuição de $0.2 \%$ como contribuição sobre a folha de pagamento das demais empresas (FPAS 647, 680, 736, 787 - Cooperativas e 833). Conforme Grabowski (2010, p. 96-97).

16 Consultar Grabowski (2010).

17 Clipagem - 18/08/2010 - "Reitores pedem a continuidade do PRONERA". Reunião com o Secretário de Recursos do TCU, Júnios Marques, para pedir a continuidade do PRONERA. Em: www.unb.br/noticias. Ainda em:

www.exkola.com.br/scripts/noticia.php?id=38101553 (Acesso em 11 set. 2010). A autora deste artigo também esteve presente a esta audiência e testemunhou a manifestação de reitores, pesquisadores e representantes da CONTAG e do MST, em defesa do PRONERA.

18 http://www.excola.com.br, acesso em 08 set. 2010.

19 "Kátia não vai à CPI do MST e quer prorrogá-la. CPMI conclui que não foi desviado recurso público para ocupações de terra". Conversa Afiada - Paulo Henrique Amorim, 16/07/2010. http://.www.conversaafiada.com.br, acesso: 08 set. 2010.

20

http://www.tvebrasil.com.br/salto/boletins2001/cms/cmstxt3.htm. PIZA,

Fernando Ferreira; SENA, Lilian Barboza. PMG3 - Escola Ativa. Acesso em 09 mar. 2010.

21 Atendendo ao Edital n. 2 da ANPED-SECAD/MEC para captação de recursos, Gustavo Bruno Bicalho Gonçalves encaminha o projeto de pesquisa: Gestão escolar e trabalho docente: um estudo do Programa Escola Ativa. Rio de Janeiro/RJ: Programa de Pós-Graduação em Políticas Públicas de Formação Humana - UERJ, jun., 2006, 17p.

22 TORRES, Rosa M. Alternativas dentro de la educación formal: el Programa Escuela Nueva de Colombia Instituto Fronesis. Quito, set., 1992, 15p. www.fronesis.org. Acesso em 24 jul. 2006 e em 06 nov. 2008. 
23 XAVIER NETO, Lauro Pires. Educação do campo em disputa: análise comparativa entre o MST e o Projeto Escola Ativa, Natal/RGN, Núcleo de Estudos em Educação. Universidade do Estado do Rio Grande do Norte, 2007. 21p. Trabalho apresentado no I Simpósio: Lutas Sociais na América Latina, em 19/07/2007, no mesmo estado/RN.

24 Ver a nota de rodapé n. 18, neste artigo.

25 O Encontro foi realizado em Fortaleza/CE, em novembro de 2004.

26 Jacqueline C. S. Freire coordenou o Relatório Final 2008 - Programa Escola Ativa: 10 anos de experiência. Diagnóstico Rápido Participativo entregue à representação do MEC, durante a realização do II Seminário Nacional de Educação do Campo, realizado em Brasília, de 6 a 8/8/2008, sob a coordenação da Universidade de Brasília - UnB. Porém não foi dado a público, por parte do MEC, o conhecimento desse Relatório.

27 Ver, sobre o assunto, Saviani (1983), Monarcha (1990) e Nunes (1996).

28 No ano de 2001 o PRONERA é incorporado ao INCRA, sendo editada a Portaria INCRA/837, aprovando a edição de um novo Manual de Operações, o qual será finalizado e aprovado pela Portaria INCRA n. 282 de 16/04/2004. Consulta na www.ced.ufsc.br/pronera/?page_id=10. Acesso 10 mai. 2012.

Recebido: $27 / 09 / 2010$

Aprovado: $15 / 04 / 2011$

Contato:

Universidade Federal do Rio Grande do Sul

Faculdade de Educação

Departamento de Estudos Básicos

Avenida Paulo Gama, s/n,

Prédio $12201 / 7^{\circ}$ andar

Centro

CEP 90460-900

Porto Alegre, RS

Brasil 